\title{
Functional analysis of autocrine and paracrine signalling at the uterine-conceptus interface in pigs
}

\author{
L. A. Jaeger ${ }^{1,2}$, G. A. Johnson"2,3* , H. Ka ${ }^{2,3}$, J. G. Garlow ${ }^{2,3}$, \\ R. C. Burghardt ${ }^{1,2}$, T. E. Spencer ${ }^{2,3}$ and F. W. Bazer ${ }^{2,3}$ \\ ${ }^{1}$ Department of Veterinary Anatomy \& Public Health, College of Veterinary Medicine, \\ ${ }^{2}$ Center for Animal Biotechnology and Genomics, and ${ }^{3}$ Department of Animal Science, \\ Texas A\&M University, College Station, TX 77843-4458, USA
}

The complexity of implantation necessitates intimate dialogue between conceptus and maternal cells, and precise coordination of maternal and conceptus signalling events. Maternal and conceptus-derived steroid hormones, growth factors and cytokines, as well as integrins and their ligands, have important and inter-related roles in mediating adhesion between apical aspects of conceptus trophectoderm and maternal uterine luminal epithelium that leads to formation of an epitheliochorial placenta. Integrin receptors appear to play fundamental roles in the implantation cascade and may interact with extracellular matrix molecules and other ligands to transduce cellular signals through autocrine and paracrine mechanisms. Functional in vitro analyses can be used to monitor individual contributions of specific integrin receptors and ligands to the signalling cascades of the maternal-conceptus interface. Integrative studies of implantation in pigs, using in vivo and in vitro approaches, are required to understand conceptus attachment and implantation in this species, and provide valuable opportunities to understand the fundamental mechanisms of implantation in all species.

\section{Introduction}

The period of conceptus attachment and implantation in pigs, as in other species, is a critical time for embryonic survival. In pigs, marked morphological and functional changes occur in the peri-implantation blastocyst, including a change in shape from a relatively small $(<10 \mathrm{~mm}$ in diameter) sphere to a filamentous form that may exceed $100 \mathrm{~mm}$ in length in $<1$ day. Coincident with and after this transformation, pig conceptuses produce a variety of secretory products, including oestrogens, interferons, proteases, growth factors and cytokines. Endometrial structure and function also change markedly and include alterations in expression of integral membrane glycoproteins as well as numerous secretory products such as protease inhibitors, growth factors and cytokines (for reviews see Burghardt et al., 1997; Geisert and Yelich, 1997). Both maternal and conceptus factors play important roles in

Email: ljaeger@cvm.tamu.edu

*Present address: Department of Animal and Veterinary Science, Agricultural Sciences Building, University of Idaho, Moscow, ID 83844-2330, USA 
maternal recognition of pregnancy and mediation of adhesion between the apical aspects of the apposing conceptus trophectoderm and maternal uterine luminal epithelium that lead to formation of an epitheliochorial placenta. The complexity of implantation necessitates intimate dialogue between conceptus and maternal cells, and precise coordination of maternal and conceptus signalling events.

Although the exact nature of the adhesive mechanisms responsible for successful implantation in pigs is not known, much evidence has been obtained that implicates interactions between integrins and extracellular matrix molecules as critical players in mammalian reproduction, particularly implantation. Which integrin-ligand combinations are required for successful implantation and maintenance of pregnancy in pigs, and the precise cellular signals they evoke to control these events, are still largely unknown. Similarly, regulation of expression of integrins and their ligands is incompletely understood, although considerable evidence points toward integrated control by steroid hormones and growth factors.

This review will focus on recent advancements in our understanding of the molecules involved in functional signalling interactions at the pre- and peri-implantation uterine-conceptus interface in pigs. In addition to examining current knowledge in pigs, signalling interactions in other species, which may provide insight into the mechanisms involved in successful implantation in pigs, will also be considered. Particular emphasis will be placed on interactions among molecules implicated directly in mediating periimplantation differentiation and adhesion, and on analyses of their mechanistic functions, as determined using in vitro experimental models. Proteases, their inhibitors and products of protease activity are important factors in implantation, but will not be discussed in detail. The discussion will first explore interactions among soluble factors, such as steroid hormones, cytokines and growth factors, and their possible roles in controlling peri-implantation growth and differentiation at the pig uterine-conceptus interface. Specific growth factors will be discussed in the context of receptor-mediating actions, those associated with binding proteins and those that may transduce signals through integrin receptors. Finally, integrins, extracellular matrix proteins and other potential integrin ligands at the uterine-conceptus interface are discussed in the context of functional signals transmitted through these molecules, and in model systems for evaluating their role in the implantation cascade.

\section{Steroid hormones and their receptors}

Implantation in pigs entails adhesion between conceptus trophectoderm and maternal endometrial luminal epithelium, leading to formation of an epitheliochorial placenta. Although the absence of invasion in this placentation strategy implies that luminal epithelium and glandular secretions are important in accomplishing successful implantation, modulation of the process by steroid hormones may be direct, via epithelial-stromal interactions or both, as described for other tissues (for review see Cooke et al., 1998). In particular, expression of receptors for progesterone, a steroid hormone that is a prerequisite for maintenance of pregnancy, decreases markedly in the luminal and glandular endometrial epithelium after day 5 of the oestrous cycle or pregnancy. Progesterone receptors are undetectable in luminal epithelium on days 12-18 of pregnancy, yet remain in the underlying stroma and myometrium (for review see Okulicz et al., 1998). Thus, stromal-derived factors, expressed under the influence of progesterone (progestomedins), may exert paracrine effects on the luminal and glandular epithelia to achieve differentiation necessary for implantation.

Between day 11 and day 12 of gestation, preimplantation pig conceptuses produce oestrogens, which are believed to comprise a critical component of the signalling mechanism 
for maternal recognition of pregnancy in pigs. A second peri-implantation phase of oestrogen production occurs between day 15 and day 30 of pregnancy (for review see Bazer et al., 1998). Oestrogen receptor mRNA and protein are present in pig endometrium during early pregnancy (for review see Okulicz et al., 1998) and mRNA content appears to correlate significantly with immunoreactive oestrogen receptor protein content (Persson et al., 1997). As oestrogen receptor $\alpha$ is present in epithelia of the pregnant uterus from day 5 to day 15 of pregnancy (for review see Okulicz et al., 1998), conceptus-derived oestrogens could exert effects on endometrial function by direct interactions with epithelial oestrogen receptors. Although stromal oestrogen receptors were not detectable between day 15 and day 18 of pregnancy, the presence of oestrogen receptors in stromal cells underlying the luminal epithelium on days 10-12 of pregnancy indicates that oestrogens may have paracrine effects on preimplantation endometrial epithelium through stromal-derived factors produced in response to oestrogens (oestromedins).

Recently, progesterone receptors and oestrogen receptors $\alpha$ and $\beta$ were identified in pig conceptuses, raising the possibility of paracrine and autocrine steroid hormone-induced effects on the conceptus during the peri-implantation phase of pregnancy.

Progesterone receptor mRNA and protein were not detectable in early (day 6) pig blastocysts (Ying et al., 2000a); however, expression of progesterone receptor was detected in filamentous conceptuses by RT-PCR (Dekaney et al, 1998; Kowalski et al., 2000). Progesterone receptor protein was localized immunohistochemically in embryonic and extraembryonic cells of conceptuses from day 10 to day 14 of gestation (Dekaney et al., 1998).

Oestrogen receptor $\alpha$ mRNA was detected by RT-PCR in pig blastocysts on day 6 of gestation; however, the corresponding protein was not detectable by immunohistochemistry (Ying et al., 2000b). In peri-implantation conceptuses from day 12 to day 14 of gestation, oestrogen receptor $\alpha$ expression was also detected by RT-PCR (Dekaney et al., 1998; Kowalski et al., 2000). Studies using immunohistochemical techniques have detected oestrogen receptor $\alpha$ protein in pig conceptus trophectoderm on days 10-12 of gestation (Dekaney et al., 1998) and oestrogen receptor $\alpha$ protein has also been identified in embryonic disk and extraembryonic cells between day 10 and day 14 (L. A. Jaeger and N. H. Ing, unpublished). Presence of oestrogen receptor $\beta$ in day 12 conceptuses has been detected via RT-PCR and western blot analysis (Kowalski et al., 2000). The functions of conceptus steroid hormone receptors remain to be determined.

\section{Growth factors and cytokines}

Numerous growth factors and cytokines have been described in pig uterus and conceptus and implicated in control of the events surrounding implantation and early pregnancy (for review see Geisert and Yelich, 1997). Here, we will address recent results on expression and effects of growth factors, cytokines and their receptors at the pig uterine-conceptus interface, with particular emphasis on those with potential autocrine and paracrine effects on adhesive interactions between endometrium and conceptuses during early pregnancy.

Interferons are antiviral cytokines which, in domestic species, are of interest as possible mediators of pregnancy recognition and establishment of pregnancy. Tau interferons (IFN- $\tau$ ) are members of a unique subclass of the type I IFN family that are produced by the conceptus trophectoderm to signal pregnancy recognition in ruminants. In sheep, IFN- $\tau$ prevents luteolysis by suppressing transcription of oestrogen receptor $\alpha$ and oxytocin receptor genes in the endometrial luminal epithelium and superficial glandular epithelium to impede the pulsatile release of $\mathrm{PGF}_{2 \alpha}$ (for review see Bazer et al., 1998). 
Peri-implantation pig conceptuses produce type I and type II interferons between day 12 and day 18 of pregnancy (for review see Bazer et al., 1998); however, their physiological role is not clear. The major species is a member of the type II IFN family (IFN- $\gamma$ ) and the other component with antiviral activity is a novel type I IFN, IFN- $\delta$ (Lefèvre et al., 1998a), which is co-expressed with IFN- $\gamma$ in the trophectoderm. Type I and II interferons in pigs do not appear to be anti-luteolytic during early pregnancy, because neither intrauterine infusion of conceptus secretory proteins collected on day 15 of pregnancy nor a mixture of recombinant IFN- $\gamma$ and IFN- $\delta$ extends the pig inter-oestrous interval (Harney and Bazer, 1989; Lefèvre et al., 1998b). Paracrine effects for IFN- $\delta$ on the uterus are suggested by localization of type I IFN receptors on endometrial epithelial cells, but not on trophoblast (see Lefèvre et al., 1998a). Chwetzoff and D'Andréa (1997) reported increased mRNA for $\beta_{2}$-microglobulin and Finkel-Biskis-Reilly murine sarcoma virus-associated ubiquitously secreted protein (FAU) in pig uterine luminal epithelial cells treated with a combination of IFN- $\gamma$ and IFN- $\delta$. A gene encoding the porcine $\mathrm{UbA}_{52}$ ubiquitin also increased in response to IFN treatment (Chwetzoff and D'Andréa, 1997) and is reminiscent of IFN induction of ISG17/UCRP, a functional homologue of ubiquitin, in ovine and bovine uterus (Hansen et al, 1997; Johnson et al., 1999a). The physiological significance of interferons during pregnancy in pigs, as well as the specific signalling pathways activated in pig endometrium, is unknown.

\section{Heparin-binding growth factors}

A growing number of growth factors and cytokines has been identified on the basis of their ability to bind to immobilized heparin. In vivo, heparin-binding growth factors bind to heparan sulphate chains, such as components of heparan sulphate proteoglycans. Hence, these growth factors can be stored or sequestered in basement membranes and extracellular matrix compartments (for review see Vlodavsky et al., 1996). As the actions of this heterogeneous group of growth factors can be altered by their interaction with extracellular matrix and regulated by release from the matrix, they are possible candidates to influence the dynamic events of implantation.

Fibroblast growth factors (FGFs) comprise a large family of growth factors with effects on cell proliferation, migration, angiogenesis, embryonic development and cellular differentiation in a variety of tissues. One of the earliest identified members, FGF-2, also known as basic FGF, has been identified in embryonic and uterine tissues of numerous species (for review see Rider and Piva, 1998). Brigstock et al. (1989) reported the presence of heparin-binding growth factors in pig uterine luminal flushings. Subsequently, several heparin-binding growth factors were purified from pig uteri, one of which was FGF-2, and another which displayed immunological crossreactivity with antiserum to FGF-1 (Brigstock et al., 1990). FGF-2 mRNA has been identified in endometrial epithelium, stroma and myometrium of gilts during the oestrous cycle and the first 30 days of pregnancy; however, no changes in expression were detected during the oestrous cycle or pregnancy (Katsahambas and Hearn, 1996). Gupta et al. (1997) reported increases in FGF-2 expression in luminal epithelium and stroma between day 10 and day 14 of pregnancy. Expression of immunoreactive FGF-1 in tissues from the same gilts was limited to stromal compartments of the uterus. Immunoreactive FGF-2, but not FGF-1, was detected in pig conceptus trophectoderm, endoderm and embryonic disk. Four distinct genes encode FGF receptors and alternative splicing of FGF receptors leads to unique ligand binding specificity of each isoform (Ornitz et al., 1996). Expression of most of these receptors at the pig maternal-conceptus interface has not been reported. Recently, FGF receptor 2 IIIb, which binds FGF-1 (Ornitz et al., 1996), was localized in endometrial luminal epithelium of pigs (Ka et al., 2000, see 
below), indicating that luminal epithelium may be a target for stromally-derived or sequestered FGF-1 during the peri-implantation period. The roles of FGF-1 and FGF-2 during early pregnancy in pigs have not been established.

FGF-7, also called keratinocyte growth factor (KGF), binds with high affinity to FGF receptor $2 \mathrm{Illb}$, a transmembrane tyrosine kinase encoded by the bek gene. Activity of FGFs, including FGF-7, is modulated further by interactions with heparan sulphate proteoglycans (see Ornitz et al., 1996). FGF-7 is a paracrine mediator of epithelial cell proliferation and expression of FGF receptor $21 \mathrm{llb}$ is restricted to epithelial cells (Finch et al., 1989; Rubin et al., 1989). In primates, FGF-7 is expressed in uterine stromal cells in response to progesterone (for review see Rider and Piva, 1998). Recently, Ka et al. (2000) cloned partial cDNAs encoding FGF-7 and FGF receptor $2 \mathrm{ll} \mathrm{b}$ from pig endometrium and detected endometrial expression of FGF-7 between day 9 and day 85 of pregnancy using slot blot hybridization. Endometrial FGF-7 expression reached a maximum on day 12 of pregnancy, coinciding with the period of oestradiol production by the conceptus and maternal recognition of pregnancy. Most surprising was localization of the FGF-7 mRNA to endometrial luminal epithelium, not stromal cells, during the pre- and peri-implantation phases and, later, to endometrial gland epithelium. Western blot analysis confirmed the presence of FGF-7 in uterine luminal flushings collected on day 12 of pregnancy. FGF receptor 2 IIIb was detected in endometrial epithelia and conceptus trophectoderm, but conceptus trophectoderm does not express FGF7 (Ka et al., 2000). This finding is indicative of unique roles for FGF-7 in uterine epithelial-epithelial and epithelial-trophectoderm autocrine and paracrine communications in pregnant pigs, which were investigated further by Ka et al. (2001).

Treatment of pig endometrial explants with oestradiol in the presence or absence of progesterone increased endometrial FGF-7 expression, whereas progesterone alone had no effect (Ka et al., 2001). Thus, conceptus oestrogens produced between day 11 and day 12 of pregnancy may be responsible for the peri-implantation peak in endometrial FGF-7 expression and, in pigs, FGF-7 appears to be an oestromedin. Possible paracrine effects of maternally derived FGF-7 on conceptus trophectoderm were investigated using a trophoblast cell line derived from day 12 pig conceptuses. Northern and slot blot analysis of FGF-7treated trophectoderm cells revealed that FGF-7 increased expression of urokinase plasminogen activator (UPA), a conceptus protease produced in vivo, coincident with periimplantation production of oestrogens. In addition, proliferation of trophectoderm was stimulated by FGF-7, as indicated by increased incorporation of tritiated thymidine into cellular DNA (Ka et al., 2001).

In addition to marked rearrangement and remodelling of trophectoderm of conceptuses during peri-implantation elongation, conceptus trophectoderm is also mitotically active during both the pre-elongation and elongation phases of development, as shown by proliferating cell nuclear antigen (PCNA) immunostaining (Wilson and Ford, 1997; Ka et al., 2001). This mitotic activity may be an important determinant of ultimate placental size and function. Wilson and Ford (2000) reported that administration of oestradiol to Meishan gilts, beginning on day 12 or day 13 of pregnancy and continuing for $48 \mathrm{~h}$, which encompasses the time of conceptus elongation and initial attachment to the endometrium, resulted in placentae that were heavier and larger than those of controls near term, albeit less efficient (as determined by fetal weight:placental mass ratios). Conceptus oestradiol production results in increased endometrial production of secretory proteins, including growth factors, such as insulin-like growth factor I (IGF-I) (for review see Simmen et al., 1995), which increases mitotic activity of trophectoderm. The increased placental size in oestrogen-treated gilts may be attributable to oestrogen-induced endometrial growth factors, such as IGF-I, which increase the rate of mitosis of peri-implantation conceptus trophectoderm (Wilson and Ford, 
2000). The work of Ka et al. $(2000,2001)$ indicates that another effector of the placental growth response may be FGF-7. There is compelling evidence for an intricate series of paracrine communication events in which oestrogens of conceptus origin, acting through epithelial and stromal endometrial oestrogen receptors, increase production of luminal epithelial growth factors, which modulate further differentiation and growth of conceptus trophectoderm to achieve successful implantation.

Connective tissue growth factor (CTCF) is another heparin-binding growth factor identified in pig uterine luminal flushings. This $38 \mathrm{kDa}$ cysteine-rich protein stimulates mitosis, migration, adhesion and extracellular matrix production in fibroblasts, and is a possible mediator of autocrine and paracrine signals in other cell types, including epithelial cells (for review see Moussad and Brigstock, 2000). In fibroblasts, CTGF mRNA is induced by TGF- $\beta$, indicating that it functions as a downstream modulator of the actions of TGF- $\beta$ in fibroblastic cells (for review see Moussad and Brigstock, 2000). The receptor or receptors used by CTGF, as well as the downstream modulators of its cellular signals, are not known. Although CTGF does not contain an RGD (arginine-glycine-aspartic acid) recognition site, it appears to possess integrin-binding capabilities, and binds to integrin $\alpha v \beta 3$ to promote migration of endothelial cells in vitro (for review see Lau and Lam, 1999).

Pig uterine luminal flushings, collected from pigs between day 0 and day 18 of the oestrous cycle or pregnancy, contain low molecular mass (10 kDa; $16-20 \mathrm{kDa}$ ) forms of CTGF (Ball et al., 1998; for review see Moussad and Brigstock, 2000); however, only a single CTGF transcript was identified in RNA collected from pig endometrium during that period (Harding et al., 1997). It was suggested that proteolytic processing was responsible for the mitogenically active low molecular mass forms of CTGF. Western blot analysis revealed that CTCF concentrations in luminal flushings on day 12 of pregnancy were higher than on day 10 of pregnancy and day 12 of the oestrous cycle. Expression of CTGF mRNA has been shown in pig endometrial stromal, vascular and endothelial cells (for review see Moussad and Brigstock, 2000); however, its detailed spatial and temporal expression patterns have not been reported. CTGF is expressed in murine embryonic and extraembryonic cells, including trophectoderm (Surveyor et al., 1998), and in uterine tissues. In humans, CTGF is present in epithelial, stromal and vascular compartments of the uterus (Uzumcu et al., 2000). In nonepithelial cells, CTGF stimulates expression of fibronectin and integrin $\alpha 5$ (for review see Moussad and Brigstock, 2000), two molecules implicated in facilitating adhesion at the pig maternal-conceptus interface; however, it is not known whether similar effects would occur in trophectoderm or uterine epithelia. The potential role of CTGF in pig implantation warrants further investigation.

\section{Insulin-like growth factors and their binding proteins}

Endometrial IGF-I is expressed coincident with maternal recognition of pregnancy in pigs. The IGF-I receptor has been identified in pig conceptus and uterine tissues, indicating potential effects of IGF-I on growth and development of the uterus and peri-implantation conceptuses (for review see Geisert and Yelich, 1997). The IGF-II/mannose-6-phosphate receptor (the role of which in IGF signalling remains unclear) has also been immunolocalized to trophectoderm of preimplantation pig conceptuses (for review see Rider and Piva, 1998). Possible roles for ICF-I in pig blastocyst development and early pregnancy have been reviewed previously (see Simmen et al., 1995; Geisert and Yelich, 1997).

More recently, ligand blot analysis revealed the presence of several IGF-binding proteins (IGFBPs), including ICFBP-3, in pig uterine luminal flushings. Abundance of the IGFBPs decreased markedly between day 11 and day 12 of gestation (Lee et al., 1998), which was 
associated temporally with conceptus transition from spherical to filamentous morphology. However, on day 12 of pregnancy, the abundance of endometrial IGFBP-3 mRNA from uteri containing spherical conceptuses was not different from that of uteri containing filamentous conceptuses. This finding indicates possible proteolytic regulation of IGFBP-3 abundance in uterine luminal flushings. In vitro analysis of IGFBP-3 proteolysis, using uterine flushes harvested on day 12 of pregnancy, indicated the presence of enzymes, including a serine protease, responsible for degradation of IGFBP-3 in uteri containing filamentous conceptuses. Regulation of intrauterine IGF actions by IGFBPs and proteases was suggested (Lee et al., 1998). Subsequently, Geisert et al. (2001) demonstrated similar proteolysis of ICFBPs in uterine flushings collected during the oestrous cycle as well as during pregnancy. They provided evidence that increased activity of the serine protease kallikrein on day 12 of the oestrous cycle and pregnancy can result in cleavage of ICFBP-2 and -3 , and that activation of matrix metalloproteinases by kallikrein may also contribute to IGFBP proteolysis within the uterine lumen.

Badinga et al. (1999) used cultures of endometrial glandular epithelial cells, established from uteri of pigs on day 12 of pregnancy, to study the effects of IGFs and IGFBPs on growth of uterine epithelial cells. Ligand blot analysis of conditioned media from the glandular epithelial cells revealed the presence of four IGFBP bands. IGF-I and IGF-II stimulated glandular epithelial cell DNA synthesis, as did an IGF-II analogue (Leu27-IGF-II), which binds the IGF-II receptor with normal binding affinity and the IGF-I receptor with low affinity. IGFBP-2, which was not identified in conditioned medium of cultured glandular epithelial cells, increased IGF-II-dependent DNA synthesis and also stimulated DNA synthesis in the absence of exogenous IGF-II. Therefore, IGF-II receptors may be involved in IGF mitogenic signalling, and IGFBP-2 may modulate uterine epithelial cell growth by IGF-dependent and -independent pathways (Badinga et al., 1999).

Although not yet examined at the pig maternal-conceptus interface, IGFBP-5 binds with high affinity to extracellular matrix proteins such as osteopontin ( $\mathrm{Nam}$ et al., 2000). Furthermore, IGFBP-1 binds integrin $\alpha 5 \beta 1$ and can alter human cytotrophoblast migration and attachment to fibronectin (Irwin and Guidice, 1998). It is possible that IGFBPs modulate activity of IGFs during early pregnancy in pigs and also affect conceptus and uterine growth and differentiation through interactions with extracellular matrix proteins or integrin receptors.

\section{Transforming growth factor $\beta s$}

Transforming growth factor $\beta$ s (TGF- $\beta \mathrm{s}$ ) 1,2 and 3 are members of a large growth factor family. These three related TGF- $\beta$ isoforms are $25 \mathrm{kDa}$ homodimeric molecules derived from precursor proteins. Each is released from cells in a latent form, resulting from continued noncovalent association with its isoform-specific homodimeric peptide, the TGF- $\beta$ latencyassociated peptide (LAP). The latent TGF- $\beta$-LAP complex is often disulphide-bonded to a latent TGF- $\beta$ binding protein implicated in secretion of the complex and its targeting to and storage in extracellular matrix. Although the mechanisms of physiological activation are still not understood fully, proteases, in particular the plasminogen activator-plasmin system, probably participate in conversion of latent TGF- $\beta$ s to active forms (for review see Rifkin et al., 1999). Once active, TCF- $\beta 1,-2$ and -3 transmit their signals through transmembrane, serinethreonine kinase type I and type II TGF- $\beta$ receptors (for review see Massague, 1998).

TGF- $\beta$ s localized to the maternal-conceptus interface in numerous species have been implicated in maternal-conceptus interactions throughout pregnancy (for review see Rider and Piva, 1998). They are of particular interest in early pregnancy because of their stimulatory 
effects on production of extracellular matrix molecules, expression of integrins and their potential to limit conceptus invasiveness by altering expression of conceptus- and uterinederived proteases and protease inhibitors.

Gupta et al. (1996) localized TGF- $\beta 1,-2$ and 3, as well as type I and II receptors, to embryonic and extraembryonic cells of pig conceptuses from day 10 (spherical morphology) to day 14 (filamentous morphology) of gestation. Yelich et al. (1997a) found that TGF- $\beta 3$ expression increased in spherical preimplantation conceptuses as they increased in size from 2-5 $\mathrm{mm}$ to $6-7 \mathrm{~mm}$ in diameter, and expression remained high throughout the tubular and filamentous stages of development. TGF- $\beta 2$ was not detected. Subsequently, expression of all three TCF- $\beta$ isoforms was detected in pig conceptuses between day 10 and day 14 of gestation. Expression of all three isoforms was greater in trophectoderm of day 14 filamentous conceptuses than in spherical day 10 conceptuses (Gupta et al., 1998a). On the maternal side of the interface, expression of TGF- $\beta 1,-2$ and -3 transcripts increased progressively in uterine luminal epithelium and stroma between day 10 and day 14 of gestation (Gupta et al., 1998a), as did expression of the TGF- $\beta$ proteins and type I and type II receptors (Gupta et al., 1998b).

Possible regulation of TGF- $\beta$ expression in the pig uterus and conceptus by maternal and possibly conceptus-derived steroids is likely. Hormonal modulation of TGF- $\beta$ expression appears to be cell type- and also isoform-specific. For example, oestradiol decreases expression of TGF- $\beta$ s in numerous cell types, but increases TGF- $\beta 1$ mRNA expression slightly and increases TGF- $\beta 3$ mRNA expression two- to three-fold in human endometrial stromal cells in culture, whereas treatment with a synthetic progestin decreases expression (Arici et al., 1996). In explant cultures derived from human proliferative phase explants, TGF- $\beta 1$ mRNA expression increased in response to a combination of oestradiol and progesterone compared with ethanol controls, but only after 4 days of culture, which may imply an indirect mechanism of induction (Casslen et al., 1998). Therefore, it is possible that each of the TGF- $\beta$ s may function as a progestomedin or oestromedin at the pig maternal-conceptus interface. Analyses of TGF- $\beta$ expression are complicated further by TGF- $\beta$ autoinduction (for review see Massague, 1998), which could occur through paracrine as well as autocrine pathways during implantation.

As TGF- $\beta$ s are produced and secreted in latent forms, the activation process represents a critical step in determining the availability and biological activity of these growth factors. Analysis of pig uterine luminal flushings with an in vitro bioassay revealed significant increases in the amounts of biologically active TGF- $\beta$ s between day 11 and day 13 of pregnancy (Gupta et al., 1998b). Thus, the growth factors increase in both absolute amounts and activity during the implantation phase to interact with TGF- $\beta$ receptors on conceptus trophectoderm, as well as maternal endometrial stromal and epithelial cells. The mechanisms responsible for activation of latent TGF- $\beta$ s at the maternal-conceptus interface are not known. However, pig conceptuses produce plasminogen activator, as well as other proteases (for review see Geisert and Yelich, 1997), during this period, which could effect activation at the apical aspect of the trophectoderm. Expression of oncofetal fibronectin and several of the integrin subunits identified at the pig maternal-conceptus interface (see below) may be upregulated by active TGF- $\beta$ s during the peri-implantation period (Gupta et al., 1998b).

Recent studies have determined novel roles for TGF- $\beta$ s in cell adhesion. Specifically, the latent TGF- $\beta$ complex and its released LAP contain RGD sequences that serve as ligands for integrin receptors such as $\alpha v \beta 1$ and $\alpha v \beta 5$. The RGD of LAP, possibly due to a conformational change, binds integrins with greater avidity after release from the latent TCF- $\beta$ complex (Munger et al., 1998). As LAP and its potential integrin receptors are present at the pig maternal-conceptus interface, LAP interactions with pig trophectoderm and uterine luminal epithelial cell integrins have been explored using an in vitro integrin activation assay (see below). 


\section{Integrins and extracellular matrix proteins}

Integrin receptors expressed by uterine endometrial epithelial cells and conceptus trophectoderm appear to play a fundamental role in the implantation adhesion cascade in mammals by virtue of their ability to bind extracellular matrix and other ligands. Integrin receptor ligation can lead to adhesion, migration, invasion and the induction of cytoskeletal reorganization and transduction of cellular signals through numerous signalling intermediates. Bi-directional signalling can involve ligand binding through an integrin receptor leading to specific effects on cytoskeletal organization and activation of signalling pathways resulting in regulation of gene expression (for review see Giancotti and Rouslahti, 1999). In addition, integrin cytoplasmic domains transduce cell type-specific signals that can modulate ligand-binding affinity. These functions of activated integrin are thought to be central to trophectoderm-uterine luminal epithelial cell interactions in pigs.

Bowen et al. (1996) reported expression of five alpha and two beta integrin subunits at the pig maternal-conceptus interface (for review see Burghardt et al., 1997). Among the most significant of their findings was increased endometrial expression of subunits $\alpha 4, \alpha 5$ and $\beta 1$ during maternal recognition of pregnancy, and upregulation of these subunits by progesterone, both in vivo and in an in vitro model of polarized uterine luminal epithelium (Bowen et al., 1996, 1997). This temporal and spatial modulation of integrin expression in luminal epithelium coincident with the reciprocal downregulation of the anti-adhesive glycoprotein Muc- 1 by progesterone may be a prerequisite for conceptus attachment. Integrin subunits $\alpha 4, \alpha 5, \alpha v, \beta 1$ and $\beta 3$ were localized at sites of contact between luminal endometrial epithelium and conceptus trophectoderm, and the heterodimers that can be formed from these subunit combinations are known receptors for extracellular matrix proteins that have been identified at the pig maternal-conceptus interface (Bowen et al., 1997). Integrin subunit $\beta 5$ is also expressed by pig peri-implantation endometrial epithelium and trophectoderm (R. C. Burghardt and M. Kim, unpublished), revealing the possibility of another integrin heterodimer that may function at the maternal-conceptus interface $(\alpha v \beta 1, \alpha 4 \beta 1, \alpha v \beta 5$ and $\alpha v \beta 3)$.

Vitronectin and fibronectin are among the extracellular matrix molecules identified at the pig maternal-conceptus interface that are capable of serving as ligands for these receptors. These extracellular matrix proteins have been implicated in murine trophoblast outgrowth and attachment, processes that can be blocked with RGD-containing peptides in vitro (Armant et al., 1986; Campbell et al., 1995). Tuo and Bazer (1996) determined that pig luminal and glandular epithelial cells, as well as trophectoderm, express a glycosylation variant of fibronectin, oncofetal fibronectin, constitutively. It is noteworthy that the human conceptus produces oncofetal fibronectin, which has been referred to as 'trophoblast glue' because it is present on invading human trophoblast (Feinberg et al., 1991). The ability of integrins expressed at the apical surface of both the maternal and fetal interface to induce fibronectin polymerization at the maternal-fetal interface may allow fibronectin to serve as a bridging ligand or 'trophoblast glue' in pigs. The ability of fibronectin to affect morphology and motility is also relevant in the context of implantation. Fibronectin is a prototype cell adhesion protein recognized by as many as ten different integrins (Johansson et al., 1997). The number of fibronectin receptors is not viewed simply as evidence of redundancy, but rather as receptors that generate different signals depending on the specific integrin receptor involved. For example, only a few fibronectin receptors play a role in the polymerization of fibronectin, two of which are relevant to implantation. Both $\alpha 5 \beta 1$ and $\alpha v \beta 3$ are involved in the formation of a fibronectin network that can be triggered on binding of the RGD sequence of fibronectin (Fogerty et al., 1990; Wennerberg et al., 1996). 
In addition to vitronectin and fibronectin present at the maternal-conceptus interface in pigs (Tuo and Bazer, 1996; Bowen et al., 1997), osteopontin is also present in pig endometrium and uterine luminal flushes from cyclic and pregnant gilts, and is expressed by endometrial epithelia (Garlow et al., 2000). Expression of osteopontin mRNA is first evident in endometrial luminal epithelium on day 12 of pregnancy and increased by day 15 of pregnancy. Expression of osteopontin in endometrial glands was not detected during early pregnancy, but was detected in uterine gland epithelium by day 35 of pregnancy. Osteopontin protein was localized on the surface of pig peri-implantation trophectoderm, whereas osteopontin mRNA was not detected, indicating that osteopontin on conceptus trophectoderm is of uterine origin. In other species, including sheep, osteopontin is a product of glandular, not luminal, endometrial epithelia (Nomura et al., 1988; Fazleabas et al., 1997; Johnson et al., 1999b,c). In fact, glandular epithelial expression of osteopontin in sheep occurs early in pregnancy, and osteopontin on the uterine luminal surface appears to be a component of histotroph from the uterine glands (Johnson et al., 2000). The novel pattern of osteopontin expression in pig endometrium may reflect the importance of the luminal epithelium in the epitheliochorial placentation strategy used by this species.

\section{Functional analysis of the implantation cascade}

It is essential to define the specific integrin responses to available matrix molecules at the maternal-fetal interface and the repertoire of signalling cascades that are activated by specific receptor-ligand activation events to understand the functional role of integrins and their ligands in implantation better. A simplified in vitro strategy used by Miyamoto et al. (1995) to define experimentally the hierarchies of cytoskeletal and signalling molecules involved in organizing the cytoskeleton and signal transduction has been adapted to investigate integrin-matrix interactions in endometrial epithelium and conceptus trophectoderm of domestic animals.

Evidence that specific extracellular matrix proteins serve as ligands for maternal and conceptus integrins can be generated in vitro by monitoring rapid induction of large cytoskeletal complexes and associated signalling intermediates which mimic those organized in focal contacts after integrin receptor-ligand occupancy and aggregation. Initiation of these complexes results from the deposition of $6 \mu \mathrm{m}$ polystyrene beads coated with relevant extracellular matrix protein ligands (Fig. 1). Controls for these experiments can include beads coated with poly-L-lysine, matrix molecules with mutated integrin recognition sequences or molecules that block integrin-matrix interactions (for example, neutralizing anti-integrin antibodies, soluble RGD-containing peptides or disintegrins). This general strategy is used to test the functional competence of integrins present at the apical surface of pig uterine luminal epithelial cells and conceptus trophectoderm cells to respond to ligands that have been identified at the maternal-conceptus interface. The induction of transmembrane aggregation of talin was selected as a response indicator in this assay because of its central role in binding cytoplasmic domains of $\beta_{1}$ and $\beta_{3}$ integrins, cytoskeletal proteins and focal adhesion kinase (Critchley, 2000).

Beads coated with LAP, the RGD-containing portion of the latent TGF- $\beta$ complex, incubated with cultured pig trophectoderm and uterine luminal epithelial cells, activated integrins on apical surfaces of both cell types by aggregation of the cytoskeletal protein talin at bead-apical membrane interfaces (Fig. 1). This finding indicates that both the latent TGF- $\beta \mathrm{s}$ and LAP released at the time of activation play direct roles in integrin-mediated adhesion and signalling between conceptus and maternal cells. Similar responses in ovine trophectoderm and uterine luminal epithelial cells indicate that this novel role for TGF- $\beta$ s in implantation is 

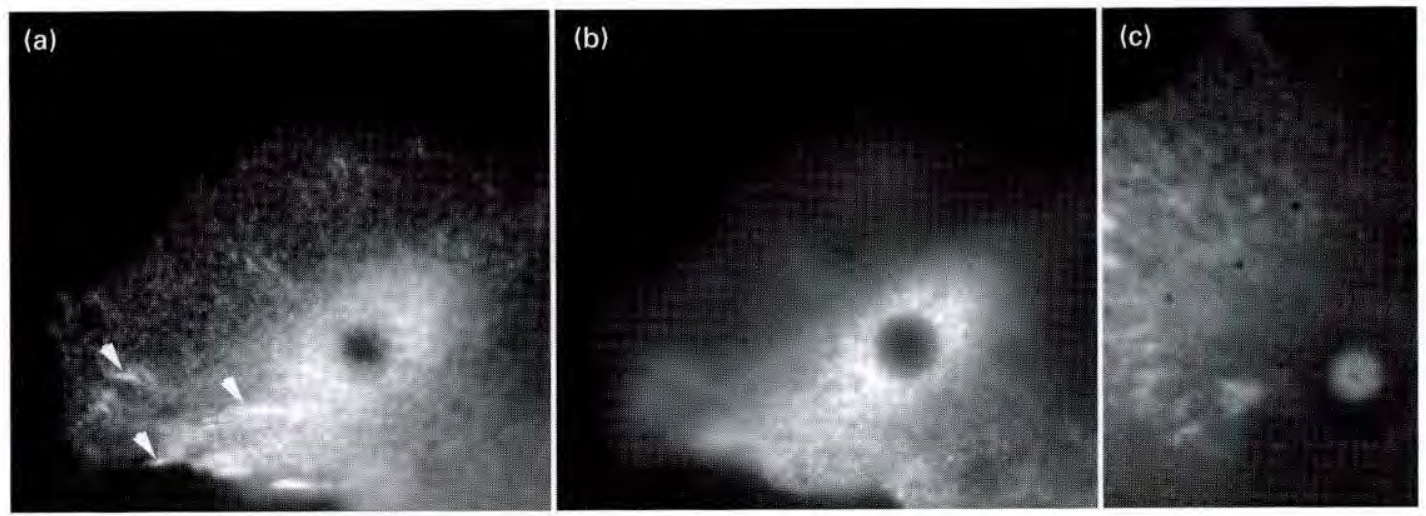

(d)

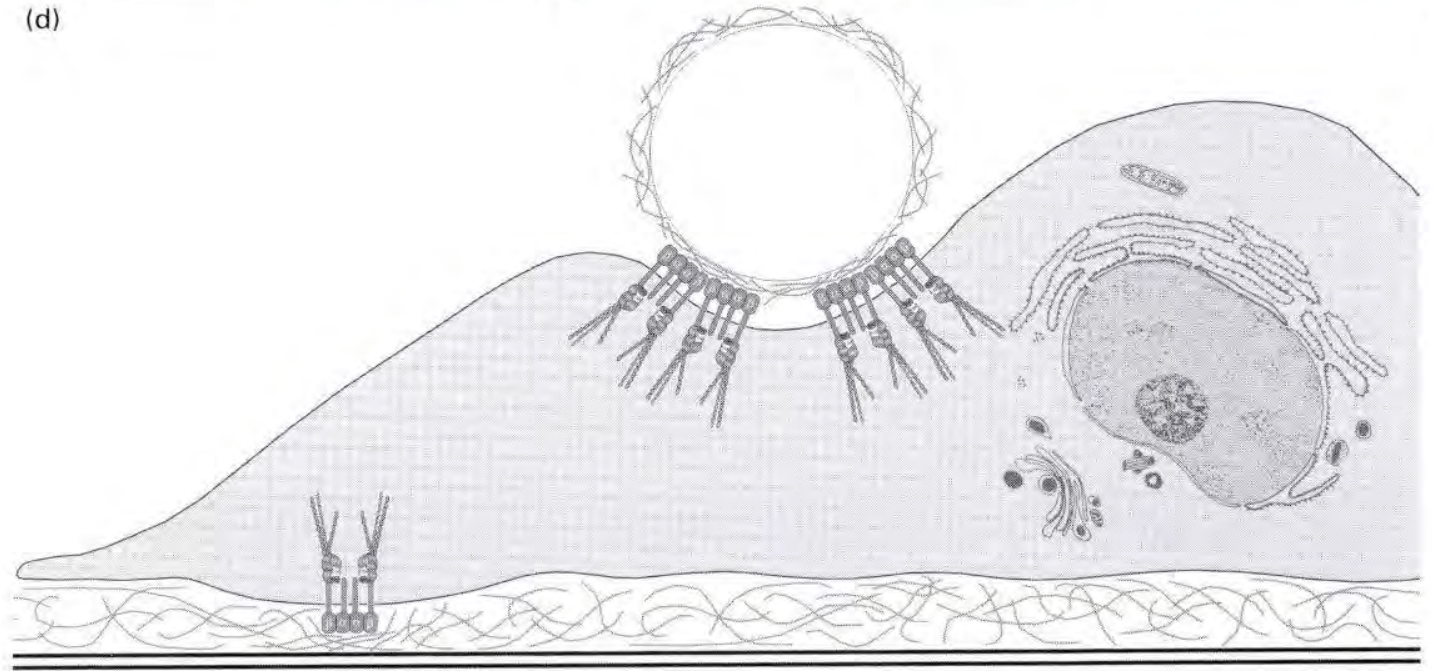

Fig. 1. Functional activation of integrin receptors on pig trophectoderm with latency-associated peptide (LAP) attached to a $6 \mu \mathrm{m}$ polystyrene bead. Reorganization of the cytoskeleton resulting from integrin activation at the surface of the bead and assembly of cytoskeletal proteins and signalling molecules on the cytoplasmic side of the integrin subunits is shown using immunocytochemical localization of the cytoskeletal protein talin. Accumulation of this protein around the beads requires integrin attachment and aggregation. (a) An optical slice obtained at the focal plane where cell attachment to the substrate reveals a series of focal adhesions (arrows) formed as the result of integrin binding to the substrate. (b) An optical slice of the same cell recorded on a focal plane above the image recorded in (a), nearing the bead-apical membrane interface. Note that basal focal adhesions are not visible in this plane. Accumulation of talin around the bead demonstrates the formation of focal adhesions that were induced by LAP activation of integrins at the apical surface of the cell. (c) Poly-Llysine-coated bead shows no evidence of focal aggregation of talin, indicating the absence of integrin involvement in the non-specific adhesive interaction of these beads with the cells. (d) Position of basal and apical focal adhesions and the basis for the assay used in these experiments. Cartoon images of aggregated integrins modified from Giancotti and Rouslahti (1999), with permission.

not unique to pigs (Jaeger et al., 2000). The precise integrins with which LAP interacts in uterine and conceptus cells, as well as the downstream signals elicited by the interactions, are not known. However, TGF- $\beta$ s may play numerous roles in modulating implantation through a complex interplay of autocrine and paracrine signalling involving binding proteins, extracellular matrix proteins and integrins, in addition to the type I and type II receptors. 
Similar analyses using fibronectin- and osteopontin-coated beads also evoked integrinactivation responses in pig and ovine trophectoderm and uterine luminal epithelial cells (Johnson et al., 2001; L. A. Jaeger, R. C. Burghardt, G. A. Johnson and F. W. Bazer, unpublished).

These studies are the first to reveal functional integrin activation and cytoskeletal reorganization in uterine luminal epithelium and trophectoderm cells in response to binding of the three matrix proteins identified in regions of initial contact between conceptus trophectoderm and uterine luminal epithelium. The receptor-ligand interactions potentially available during attachment in pigs are shown (Table 1). Clearly, dissection of the individual contributions of each receptor and each extracellular matrix protein will benefit from exploitation of in vitro models using biochemical approaches and modern imaging tools that facilitate non-invasive assessment of integrin-mediated signal transduction.

It is possible that each integrin heterodimer present at the apical surfaces of these cells $(\alpha v \beta 1, \alpha 4 \beta 1, \alpha 5 \beta 1, \alpha v \beta 3$ and $\alpha v \beta 5)$ functions as a receptor for the matrix proteins identified to date. However, this is not viewed as redundancy because different signalling cascades can be activated by different receptors. For example, $\alpha 5 \beta 1$ and $\alpha v \beta 3$ are involved in fibronectin polymerization but the affinity of $\alpha v \beta 3$ for fibronectin is much lower and contributes little to cell adhesion to fibronectin (Johansson et al., 1997). Furthermore, these integrins trigger distinct intracellular signalling pathways (Schwartz and Denninghoff, 1994). Some integrins present on pig conceptus and endometrial epithelium may influence the actions of one another. In endothelial cells, for example, interactions between fibronectin and integrin $\alpha 5 \beta 1$ potentiate $\alpha v \beta 3$-mediated migration on vitronectin (Kim et al., 2000). This type of response may have a greater influence on the trophectoderm side of the maternal-fetal interface because of the dynamic events that bring trophectoderm in contact with the luminal epithelium. Finally, particular integrin-matrix protein interactions may occur in a precise, temporal sequence during the progressive attachment of the conceptus to the uterine luminal epithelium.

Several possible models of integrin-matrix protein interactions are apparent on the basis of expression of particular integrins and extracellular matrix proteins that may serve as ligands at attachment sites (Fig. 2). Firstly, these interactions may facilitate attachment by binding of conceptus integrins to matrix proteins expressed on the luminal epithelium, and vice versa. Secondly, molecules such as osteopontin, a component of histotroph with more than one potential integrin binding site, or fibronectin, which can exist in a polymerized state, may serve as 'bridging ligands' between the two apposing epithelia. Thirdly, localized autocrine actions of ligands expressed at the cell surface with apically expressed integrins may be important. This may be of particular importance as the elongating trophoblast undergoes marked morphological change in preparation for attachment. On approximately day 12 of gestation, the morphology of the conceptus undergoes a marked change from a small sphere to a long filamentous form, accompanied by alterations in trophectodermal cytoskeletal architecture (for review see Geisert and Yelich, 1997). In addition, gene expression in trophectoderm changes during the transition from non-filamentous to filamentous conceptuses (Yelich et al., 1997b; Wilson et al., 2000). The mechanisms responsible for the marked changes that occur in preparation for attachment are not known. Given the marked rearrangement of the trophectoderm actin cytoskeleton and the intimate relationship between activated integrins and the cytoskeleton it is possible that some of the morphological alterations and associated changes in gene expression result from integrin activation. Molecules produced by pig trophoblast, such as oncofetal fibronectin and the TGF- $\beta$ LAP are possible candidate ligands for effecting this type of autocrine activation of integrin. 


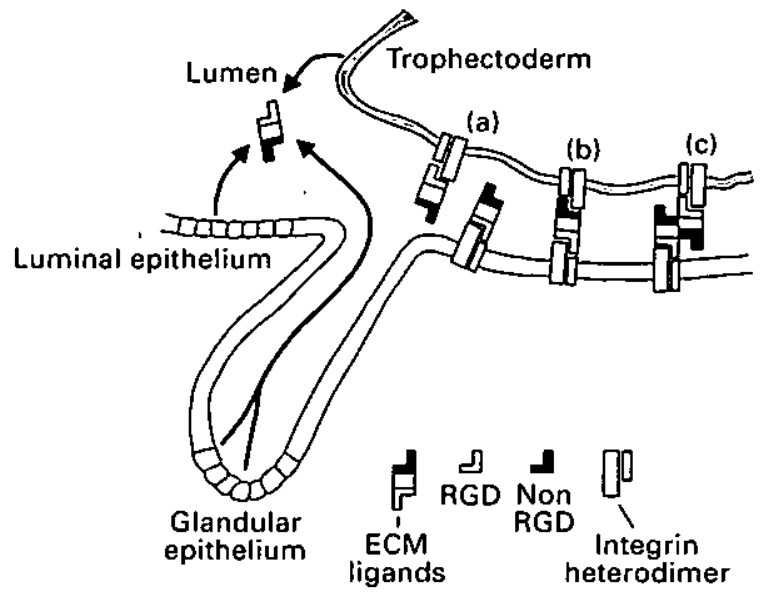

Fig. 2. Proposed model for extracellular matrix protein-integrin interactions at the maternal-conceptus interface. Extracellular matrix proteins (ECM ligands), produced by endometrial or conceptus epithelia, may interact with integrin heterodimers on apical aspects of trophectoderm and luminal epithelial cells via (a) arginine-glycine-aspartic acid (RGD) sequences and (b) non-RGD sequences. As ECM ligands such as osteopontin and fibronectin may contain more than one integrin binding site, they may function as 'bridging ligands' to facilitate conceptus attachment to the luminal epithelium in (b) monomeric or (c) polymeric forms. Modified from Johnson et al. (1999b), with permission.

\section{Conclusion}

Available results indicate that unravelling the complex signalling between maternal and conceptus cells requires integrative approaches using both in vivo and in vitro models. Pig trophectoderm cells, which are the source of conceptus-derived oestrogens, express numerous growth factors and growth factor receptors, and interact directly with maternal luminal uterine epithelium during implantation. Various in vitro models, including isolated trophectodermal cells and trophectodermal vesicles, have been used to study autocrine and paracrine activities of pig trophoblast and its contribution to successful establishment of pregnancy. In addition to primary culture models, feeder-dependent (Flechon et al:, 1995) and feeder-independent (Ramsoondar et al., 1993; Ka et al., 2001) pig trophectodermal cell lines have been developed from pre- and peri-implantation pig conceptuses. Similarly, primary cultures of uterine cells and tissues assist in evaluation of the complex signalling occurring at the maternal-conceptus interface. Co-culture models consisting of uterine stromal and epithelial cells, and culture of polarized epithelial cells supported by extracellular matrices, are useful for studying maternal autocrine and paracrine signalling during early pregnancy. Recently, immortalized cell lines representing luminal epithelium, glandular 
Table 1. Possible ligand-integrin interactions at the pig uterine-conceptus interface

Ligands identified at the maternal-conceptus interface Apically expressed integrin heterodimers

Oncofetal fibronectin/fibronectin $\alpha \vee \beta 1, \alpha 5 \beta 1, \alpha 4 \beta 1$ Osteopontin $\alpha \vee \beta 1, \alpha 4 \beta 1, \alpha \vee \beta 5, \alpha \vee \beta 3$ Vitronectin $\alpha \vee \beta 1, \alpha v \beta 5, \alpha v \beta 3$ TGF- $\beta$ latency-associated peptide $\alpha \vee \beta 1, \alpha v \beta 5, \alpha \vee \beta 3$

TCF- $\beta$ : transforming growth factor $\beta$.

epithelium, stroma and myometrium of pig uterus were developed using a retroviral vector containing the E6 and E7 human papillomavirus oncogenes (Wang et al., 2000). These cells maintain many characteristics of their in vivo counterparts, including oestrogen and progesterone receptors, and thus provide useful models for studying cell-type specific uterine signalling.

Pigs, which have true epitheliochorial placentation, show some unique paracrine signalling, such as production of FGF-7 and osteopontin by luminal epithelium, which may provide insight into which molecules and mechanisms are critical for establishment of pregnancy in other species. As a result of the importance of 'histotroph' for pig conceptus development and maintenance of pregnancy, the pig is an attractive model for study of autocrine and paracrine signalling mediated by growth factors, cytokines and binding proteins. The non-invasive nature of placentation in this species offers unique opportunities to study mechanisms of adhesion that are not complicated by erosion of maternal endometrium. Other domestic species, such as sheep and goats, with syndesmochorial placentation, and horses, with chorionic girdle formation followed by diffuse epitheliochorial placentation, also offer distinctive features to aid in understanding the conceptus-maternal communication leading to successful implantation and placentation. Comparative studies of implantation in domestic livestock species with non-invasive implantation and in primates and rodents with invasive implantation provide valuable opportunities to understand fundamental mechanisms of implantation in all species.

Steroid hormones, growth factors and cytokines, as well as integrins and their ligands, are intertwined intricately in mediating pig implantation. Integrins, with their potential to transmit signals to maternal and conceptus cells, as well as bridge apposing epithelia, are probably major participants in mediation of peri-implantation differentiation of conceptus and maternal cells, and accomplishment of stable conceptus attachment to the endometrial epithelium. Maternal and conceptus steroids are critical components in the dialogue between maternal and conceptus cells and probably exert their effects directly and through growth factor mediators to affect epithelial cell functions. Current evidence supports roles for growth factors and their associated proteins to regulate expression of integrins and their ligands, and, importantly, to participate directly in integrin-mediated signalling.

Research was supported by USDA-NRICGP grants 98-35203-6223 and 95-37203-2185 to R. C. Burghardt and F. W. Bazer, USDA-NRICGP grant 2000-02290 to F. W. Bazer and L. A. Jaeger, and by NIH 1-F32HD08501-01A1 to G. A. Johnson. Use of microscopy and imaging facilities in the College of Veterinary Medicine Image Analysis Laboratory, which are supported, in part, by NIH Grant P30 ES09106, is acknowledged. 


\section{References}

Arici A, MacDonald PC and Casey ML (1996) Modulation of the levels of transforming growth factor $\beta$ messenger ribonucleic acids in human endometrial stromal cell Biology of Reproduction 54 463-469

Armant DR, Kaplan HA, Morer H and Lennarz WI (1986) The effects of hexapeptides on attachment and outgrowlh of mouse blastocysts cultured in vitro: evidence for the involvement of the cell recognition tripeptide Arg-Gly-Asp Proceedings National Academy of Sciences USA 83 6751-6755

Badinga L, Song S, Simmen RC, Clarke JB, Clemmons DR and Simmen FA (1999) Complex mediation of uterine endometrial epithelial cell growth by insulin-like growth factor-II (IGF-II) and IGF-binding protein-2 Journal of Molecular Endocrinology 23 277-285

Ball DK, Surveyor GA, Diehl JR, Steffen CL, Uzumcu M, Mirando MA and Brigstock DR (1998) Characterization of 16- to 20-kilodalton ( $\mathrm{kDa}$ ) conneclive tissue growth factors (CTGFs) and demonstration of proteolytic activily for $38-\mathrm{kDa}$ CTGF in pig uterine luminal f́lushings Biology of Reproduction 59 828-835

Bazer FW, Ott TL and Spencer TE (1998) Endocrinology of the transition from recurring estrous cycles to establishment of pregnancy in subprimate mammals. In Endocrinology of Pregnancy pp 1-34 Ed. FW Bazer. Humana Press, New Jersey

Bowen JA, Bazer FW and Burghardt RC (1996) Spatial and temporal analyses of integrin and Muc- 1 expression in porcine uterine luminal epithelium and trophectoderm in vivo. Biology of Reproduction 55 1098-1 106

Bowen JA, Bazer FW and Burghardt RC (1997) Spatial and temporal analyses of integrin and Muc-1 expression in porcine uterine luminal epithelium and trophectoderm in vitro. Biology of Reproduction $56409-415$

Brigstock DR, Heap RB and Brown KD (1989) Polypeptide growth factors in uterine tissues and secretions fournal of Reproduction and Fertility 85 747-758

Brigstock DR, Heap RB, Barker PJ and Brown KD (1990) Purification and characterization of heparin-binding growth factors from porcine uterus Biochemical Journal 266 273-282

Burghardt RC, Bowen JA, Newton GR and Bazer FW (1997) Extracellular matrix and the implantation cascade in pigs fournal of Reproduction and Fertility Supplement 52 151-164

Campbell S, Swann HR, Seif MW, Kimber SJ and Aplin JD (1995) Cell adhesion molecules on the oocyte and preimplantation human embryo Human Reproduction 10 1571-1578

Casslen B, Sandberg T, Gustavsson B, Willen R and Nilbert $M$ (1998) Transforming growth f́actor $\beta 1$ in the human endometrium. Cyclic variation, increased expression by estradiol and progesterone, and regulation of plasminogen activators and plasminogen activator inhibitor 1 Biology of Reproduction 58 1343-1350

Chwetzoff $\mathbf{S}$ and D'Andréa $\mathbf{S}$ (1997) Ubiquilin is physiologically induced by interferons in luminal epithelium of porcine uterine endometrium in early pregnancy - global RT-PCR CDNA in place of RNA for differential display screening FEBS Letters 405 148-152

Cooke PS, Buchanan DL, Kurita T, Lubahn DB and Cunha GR (1998) Stromal-epithelial cell communication in the female reproductive tract. In Endocrinology of Pregnancy pp 491-506 Ed. FW Bazer. Humana Press, New Jersey

Critchley DR (2000) Focal adhesions - the cytoskeletal connection Current Opinions in Cell Biology 12 133-139

Dekaney CM, Ing NH, Bustamante L, Madrigal MM and Jaeger LA (1998) Estrogen and progesterone periimplantation porcine conceptuses Biology of Reproduction 58 (Supplement 1) 92 (Alsstract)

Fazleabas AT, Bell SC, Fleming S, Sun 1 and Lessey BA (1997) Distribution of integrins and the extracellular matrix proteins in the baboon endometrium during the menstrual cycle and early pregnancy Biology of Reproduction 56 348-356

Feinberg RF, Kliman HJ and Lockwood CJ (1991) Is oncofetal fibronectin a trophoblast glue for human implantation? American Journal of Pathology 138 $537-543$

Finch PW, Rubin JS, Miki T, Ron D and Aaronson SA (1989) Human KGF is FGF-related with properties of a paracrine effector of epithelial cell growth Science 245 $752-755$

Flechon JE, Laurie S and Notarianni E (1995) Isolation and characterization of a feeder-dependent, porcine trophectoderm cell line obtained from a 9-day blastocyst Placenta 16 643-658

Fogerty F), Akiyama SK, Yamada KM and Mosher DF (1990) Inhibition of binding of fibronectin to matrix sites by anti-integrin (alpha5 31 ) antibodies Journal of Cell Biology 111 699-708

Garlow JE, Ka H, Johnson GA, Jaeger LA, Burghardt RC and Bazer FW (2000) Role of osteopontin during early pregnancy in pigs Biology of Reproduction 62 (Supplement 1) 282 (Abstract)

Geisert RD and Yelich IV (1997) Regulation of conceptus development and attachment in pigs fournal of Reproduction and Fertility Supplement 52 133-149

Geisert RD, Chamberlain CS, Vonnahme KA, Malayer IR and Spicer LI (2001) Possible role of kallikrein in proteolysis of insulin-like growth factor binding proteins during the oestrus cycle and early pregnancy in pigs Reproduction $121>19-728$

Giancotti FG and Rouslahti E (1999) Integrin signalling Science 285 1028-1032

Gupta A, Bazer FW and Jaeger LA (1996) Differential expression of TGF $\beta$ s $(T C F \beta 1, T G F \beta 2, T G F \beta 3$ ) and their receptors (Type $\mathrm{I}$ and Type II) in peri-implantation porcine conceptuses Biology of Reproduction 55 796-802

Gupta A, Bazer FW and Jaeger LA (1997) Immunolocalization of acidic and basic fibroblast growth factors in porcine uterine and conceptus tissues Biology of Reproduction $5615227-15536$

Gupta A, Ing NH, Bazer FW, Bustamante LS and faeger LA (1998a) Beta transforming growth factors (TGFBs) at the 
porcine conceptus-maternal interface. Part I: expression of TGF $\beta 1$, TGF $\beta 2$, and TCF $\beta 3$ messenger ribonucleic acids Biology of Reproduction 59 905-910

Gupta A, Dekaney CM, Bazer FW, Madrigal MM and Jaeger LA (1998b) Beta transforming growth factors (TCF $\beta$ s) at the porcine conceptus-maternal interface. Part II: uterine TGF $\beta$ bioactivity and expression of immunoreactive TGF $\beta$ s (TGF $\beta 1, T G F \beta 2$, and TGF 33 ) and their receptors (Type I and Type 11) Biology of Reproduction 59 911-917

Hansen TR, Austin KJ and Johnson GA (1997) Transient ubiquitin cross-reactive protein gene expression in bovine endometrium Endocrinology 138 5079-5082

Harding PA, Surveyor GA and Brigstock DR (1997) Characterization of pig connective tissue grouvth factor (CTCF) CDNA, mRNA and protein from uterine tissue DNA Sequence - The Journal of Sequencing and Mapping 8 385-390

Harney IP and Bazer FW (1989) Effect of porcine conceptus secretory proteins on interestrous interval and uterine secretion of prostaglandins Biology of Reproduction 41 277-284

Irwin JC and Guidice LC (1998) Insulin-like growth factor binding protein-1 binds to placental cytotrophoblast $\alpha 5 \beta 1$ integrin and inhibits cytotrophoblast invasion into decidualized endometrial stromal cultures Growth Hormone and ICF Research 8 21-31

Jaeger LA, Burghardt RC, Johnson GA and Bazer FW (2000) Activation of conceptus and maternal integrins by transforming growth factor beta latency associated peptide Biology of Reproduction 62 (Supplement 1) 281 (Abstract)

Johansson S, Svineng G, Wennerberg K, Armulik A and Lohikangas L (1997) Fibronectin-integrin interactions Frontiers in Bioscience 2 126-146

Johnson GA, Spencer TE, Hansen TR, Austin KJ, Burghardt RC and Bazer FW (1999a) Expression of the interferontau inducible ubiquilin cross-reactive protein in the ovine uterus Biology of Reproduction 61 312-318

Johnson GA, Burghardt RC, Spencer TE, Newton GR, Ott TL and Bazer FW (1999b) Ovine osteopontin: II. Osteopontin and $\alpha_{4} \beta_{3}$ integrin expression in the uterus and conceptus during the peri-implantation period Biology of Reproduction 61 892-899

Johnson GA, Spencer TE, Burghardt RC and Bazer FW (1999c) Ovine osteopontin: I. Cloning and expression of mRNA in the uterus during the peri-implantation period Biology of Reproduction 61 884-891

Johnson GA, Spencer TE, Burghardt RC, Taylor KM, Gray $\mathrm{CA}$ and Bazer FW (2000) Progesterone modulation of osteopontin gene expression in the ovine uterus Biology of Reproduction 62 1315-1321

Johnson GA, Bazer FW, Jaeger LA, Ka H, Garlow JE, Piarrer C, Spencer TE and Burghardt RC (2001) Muc-1, integrin and osteopontin expression during the implantation cascade in sheep Biology of Reproduction $65820-828$

Ka H, Spencer TE, Johnson GA and Bazer FW (2000) Keratinocyte growth factor: expression by endometrial epithelia of the porcine uterus Biology of Reproduction $621771-1778$
Ka H, Jaeger LA, Johnson GA, Spencer TE and Bazer FW (2001) Keratinocyte growth factor is up-regulated by estrogen in porcine uterine endometrium and functions in trophectoderm cell proliferation and differentiation Endocrinology 142 2303-2310

Katsahambas S and Hearn MTW (1996) Localization of basic fibroblast growth factor mRNA (FGF-2 mRNA) in the uterus of mated and unmated gilts journal of Histochemistry and Cytochemistry 44 1289-1302

Kim S, Harris M and Varner JA (2000) Regulation of integrin $\alpha \vee \beta 3$-mediated endothelial cell migration and angiogenesis by integrin $\alpha 5 \beta 1$ and protein kinase $A$ journal of Biological Chemistry $27533920-33928$

Kowalski AA, Graddy LG, Choi I, Katzenellenbogen BS, Simmen FA and Simmen RCM (2000) Expression of estrogen receptor (ER)- $\alpha$ and $-\beta$ and progesterone receptor (PR) by porcine embryos suggests potential autocrine functions in development Biology of Reproduction 62 (Supplement 1) 106 (Abstract)

Lau LF and Lam SC-T (1999) The CCN family of angiogenic regulators: the integrin connection Experimental Cell Research 248 44-57

Lee CY, Green ML, Simmen RC and Simmen FA (1998) Proteolysis of insulin-like growth factor-binding proteins (IGFBPs) within the pig uterine lumen associated with peri-implantation conceptus development journal of Reproduction and Fertility 112 369-377

Lefêvre $F$, Guillomot $M$, D'Andréa S, Battegay $S$ and La Bonnardière C (1998a) Interferon-delta: the first member of a novel type $I$ interferon family Biochimie 80 779-788

Lefévre F, Martinatbotte F, Locatelli A, Deniu P, Terqui M and La Bonnardière $C$ (1998b) Intrauterine infusion of high doses of pig trophoblast interferons has no antiluteolytic effect in cyclic gilts Biology of Reproduction 58 1026-1031

Massague I (1998) TGF- $\beta$ signal Iransduction Annual Reviews in Biochemistry 67 753-791

Miyamoto S, Teramoto H, Coso OA, Gutkind IS, Burbelo PD, Akiyama SK and Yamada KM (1995) Integrin function: molecular hierarchies of cytoskeletal and signaling molecules fournal of Cell Biology 131 $791-805$

Moussad EE and Brigstock DR (2000) Connective tissue growth íactor: what's in a name? Molecular Genetics and Metabolism 71 276-292

Munger JS, Harpel JG, Giancotti FG and Rifkin DB (1998) Interactions between growth íactors and integrins: latent forms of transforming growth factor- $\beta$ are ligands for integrin $\alpha v \beta 1$ Molecular Biology of the Cell 9 2627-2638

Nam TJ, Busby WH, Jr, Rees C and Clemmons DR (2000) Thrombospondin and osteopontin bind to insulin-like growth factor (IGF)-binding protein-5 leading to an alteration in IGF-I-stimulated cell growth Endocrinology 141 1100-1106

Nomura S, Wills AJ, Edwards JK, Heath JK and Hogan BLM (1988) Developmental expression of 2ar (osteopontin) and SPARC (osteonectin) RNA as revealed by in situ hybridization fournal of Cell Biology 106 441-450

Okulicz WC, Hild-Petito S and Chilton B (1998) Expression of steroid hormone receptors in the pregnant uterus. In 
Endocrinology of Pregnancy pp 177-197 Ed. FW Bazer. Humana Press, New Jersey

Ornitz DM, Xu J, Colvin JS, McEwen DG, MacArthur CA, Coulier F, Gao G and Goldfarb M (1996) Receptor specificity of the fibroblast growth factor family journal of Biological Chemistry 271 15 292-15297

Persson E, Sahlin L, Masironi B, Dantzer V, Eriksson $H$ and Rodriguez-Martinez H (1997) Insulin-like growth factor-I in the porcine endometrium and placenta localization and concentration in relation to steroid influence during early pregnancy Animal Reproduction Science 46 261-281

Ramsoondar J, Christopherson RJ, Guilbert LJ and Wegmann TG (1993) A porcine trophoblast cell line that secretes growth factors which stimulate porcine macrophages Biology of Reproduction 49 681-694

Rider $V$ and Piva $M$ (1998) Role of growth factors of uterine and fetal-placental origin during pregnancy. In Endocrinology of Pregnancy pp 83-124 Ed. FW Bazer. Humana Press, New Jersey

Rifkin DB, Mazzieri R, Munger JS, Moguera I and Sung J (1999) Proteolytic control of growth f́actor availability APMIS 107 80-85

Rubin IS, Osada H, Finch PW, Taylor WC, Rudikoff S and Aaronson SA (1989) Purification and characterization of a newly identified growth factor specific for epithelial cells Proceedings National Academy of Sciences USA 86 8022-8026

Schwartz MA and Denninghoff K (1994) Alpha $v$ integrins mediate the rise in intracellular calcium in endothelial cells on fibronectin even though they play a minor role in adhesion Journal of Biological Chemistry 26911 133-11 137

Simmen RCM, Green ML and Simmen FA (1995) IGF system in periimplantation uterus and embryonic development. In Molecular and Cellular Aspects of Periimplantation Processes pp 185-204 Ed. SK Dey. Springer-Verlag, New York

Surveyor GA, Wilson AK and Brigstock DR (1998) Localization of connective tissue growth f́actor during the period of embryo implantation in the mouse Biology of Reproduction 59 1207-1213

Tuo WB and Bazer FW (1996) Expression of oncofetal fibronectin in porcine concepluses and uterus throughout gestation Reproduction, Fertility and Development 8 1207-1213
Uzumcu M, Homsi MF, Ball DK, Coskun S, Jaroudi K, Hollanders JM and Brigstock DR (2000) Localization of connective tissue growth factor in human uterine tissues Molecular Human Reproduction 6 1093-1098

Vlodavsky I, Miao H-Q, Medalion B, Danagher P and Ron D (1996) Involvement of heparan sulfate and related molecules in sequestration and growth promoting activity of fibroblast growth factor Cancer and Metastasis Reviews 15 177-186

Wang G, Johnson GA, Spencer TE and Bazer FW (2000) Isolation, immortalization, and initiall-characterization of uterine cell lines: an in vitro model system for the porcine uterus in Vitro Cellular and Developmental Biology 36 650-656

Wennerberg K, Lohikangas L, Gullberg D, Pfaff $M$, Johansson $S$ and Fässler $R$ (1996) $\beta 1$ integrin-dependent and -independent polymerization of fibronectin Journal of Cell Biology 132 227-238

Wilson ME and Ford SP (1997) Differences in trophectoderm mitotic rate and P450 17-alpha-hydroxylase expression between late preimplantation Meishan and Yorkshire conceptuses Biology of Reproduction 56 380-385

Wilson ME and Ford SP (2000) Effect of estradiol-17 beta administration during the time of conceptus elongation on placental size at term in Meishan pigs fournal of Animal Science 78 1047-1052

Wilson ME, Sonstegard TS, Smith TPL, Fahrenkrug SC and Ford SP (2000) Differential gene expression in the preimplantation pig embryo Cenesis 26 9-14

Yelich JV, Pomp D and Geisert RD (1997a) Detection of transcripts for retinoic acid receptors, retinol-binding protein, and transforming growlh factors during rapid trophoblastic elongation in the porcine conceptus Biology of Reproduction 57 286-294

Yelich JV, Pomp D and Geisert RD (1997b) Ontogeny of elongation and gene expression in the early developing porcine conceptus Biology of Reproduction 57 1256-1265

Ying CW, Yang YC, Hong WF, Cheng WTK and Hsu WL (2000a) Progesterone receptor gene expression in preimplantation pig embryos European fournal of Endocrinology 143 697-703

Ying CW, Hsu WL, Hong WF, Cheng WTK and Yang YC (2000b) Estrogen receptor is expressed in pig embryos during preimplantation development Molecular Reproduction and Development 55 83-88 